\title{
Do Therapeutic Exercises Improve Kinesophobia and Health-Related Quality of Life in Adult Hemophilia Patients? A Randomized Controlled Trial
}

\author{
Volkan DENIZ1* $^{1^{\text {(D) }}}$, Nevin A. GÜZEL ${ }^{2}$ (D)
}

\author{
${ }^{1}$ Department of Physical Therapy and Rehabilitation, Faculty of Health Sciences, Gazi University \\ ${ }^{2}$ Department of Physical Therapy and Rehabilitation, Faculty of Health Sciences, Gazi University \\ *Corresponding author: volkand2014@ gmail.com
}

\begin{abstract}
Objectives: Pain, risk of injury and physical limitations lead to the development of kinesiophobia and decrease in healthrelated quality of life in hemophilia patients. The aim of this study was to investigate the effects of therapeutic exercises on kinesiophobia and health-related quality of life in adult hemophilia patients. Material and Methods: A total of 24 patients aged 18 to 42 years were included in the study. Patients were randomly allocated to the control and exercise groups. Tampa Scale of Kinesiophobia (TSK) was used for evaluation of kinesiophobia; Short Form-36 (SF-36) and Hemophilia Adult Quality of Life (Hem-A-Qol) were used to assess health related quality of life. These evaluation scales were applied on the participants of both groups before and at the end of the study. Therapeutic exercises program including, warm up, resistive, stretching and balance exercises and information about positive effects of exercises on hemophilic arthropathy were administered to the exercise group three days a week for two months. Control group received only verbal information same as exercise group. Results: At baseline in physical, sociodemographic-clinical data, SF-36 and Hem-A-Qol scores there was not a significant difference between groups $(p>0.05)$. However, in kinesiophobia level, there was a significant difference in favor of the control group $(p<0.05)$. After the exercise program, there was a significant decrease in kinesiophobia and increase in total SF-36 score in the exercise group compared to the control group $(p<0.05)$. However, there was a decrease clinically in favor of the exercise group in total Hem-A-Qol value, this difference was not statistically meaningful $(p>0.05)$. Conclusions: Therapeutic exercises are simple and safe treatment modalities that can be used to improve kinesiophobia and health-related quality of life in adult hemophilia patients.
\end{abstract}

Keywords

Hemophilia, Kinesiophobia, Quality of Life

\section{INTRODUCTION}

Hemophilia is a hemorrhagic disease progressed due to the lack of some coagulant factors (factor VIII: hemophilia A, factor IX: hemophilia B) (White et al., 2001). In terms of factor efficiency, the classification of hemophilia on various levels (severe : $<\% 1$, medium: \%1-\%5 and mild: \%5-\%40) is performed. Recurrent musculoskeletal hemorrhages related to the lack of coagulant factors cause arthropathy characterized by severe degeneration in joint cartilage and subchondral bones (Fischer et al., 2016 \& Witkop et al., 2017). The structures most affected by bleeding are knee, ankle and elbow joints. In case of bleeding in these joints, they are defined as the 'target joint'. Target joint formation in people with hemophilia causes to decrease of physical activity level (Stephenson et al., 2009). Decrease in the physical activity level developed by joint pain and limitations are the most important reason in worsening the health related quality of life (HRQoL) (Hartl et al., 2008). 
Kinesiophobia is a person's state of having the fear of doing physical activity characterized by the sense of vulnerability against the risk of painful injury or the risk of being injured again (Vlaeyen et al., 1995). On individuals with particularly chronic musculoskeletal dysfunction and pain, kinesiophobia phenomenon is encountered frequently (Luque-Suarez et al., 2018). Kinesiophobia has a negative effect on the rehabilitation process. For this reason, it has to be taken into consideration and should be treated. Kinesiophobia management includes gradual exercise applications and cognitive-behavioral methods (Sethy and Sahoo, 2018). On hemophilic adult individuals, pain, risk of injury and lack of motivation cause the level of physical activities to decrease but, on the other hand, the phenomenon of kinesiophobia to increase. While there are some arguments in literature that multiple and safe exercise programs will increase the HR-QoL and decrease kinesiophobia on hemophilic patients (Lehmeier et al., 2018), no study about this issue is encountered. The aim of this study was to research the influences of regularly applied therapeutic exercise program on kinesiophobia and HR-QoL in hemophilic adults. The following hypotheses were investigated: therapeutic exercise improve (i) kinesiophobia and (ii) HR-QoL in hemophilic adults.

\section{MATERIALS AND METHODS}

\section{Study Design}

The study was performed randomized and controlled between July-September 2019 in one center and was approved by local ethics committee affiliated to the university (14.06.2019-89/56). The participants were informed about the study and their written consents were obtained. All procedures were conducted being in line with Helsinki Declaration. The study protocol was recorded in clinicaltrials.gov (NCT04205188).

\section{Patient Participation and Randomization}

Twenty-four individuals with hemophilia were enrolled in this study. They were selected from in $\mathrm{Y}$ region of $\mathrm{X}$ country. Individuals living in this region were informed through ether meeting or phone call about study. Those whose social and physical conditions were appropriate and who accepted to participate in this study were evaluated in terms of study criteria. Individuals older than 18, diagnosed with hemophilia A or B, without any cognitive problems and who literate were included in the study. On the other hand, those with another congenital coagulopathy such as Von Willebrand Syndrome, unable to walk due to hemophilic arthropathy and with whom inhibition arose against factor VIII-IX were excluded from the study (Figure 1 ).

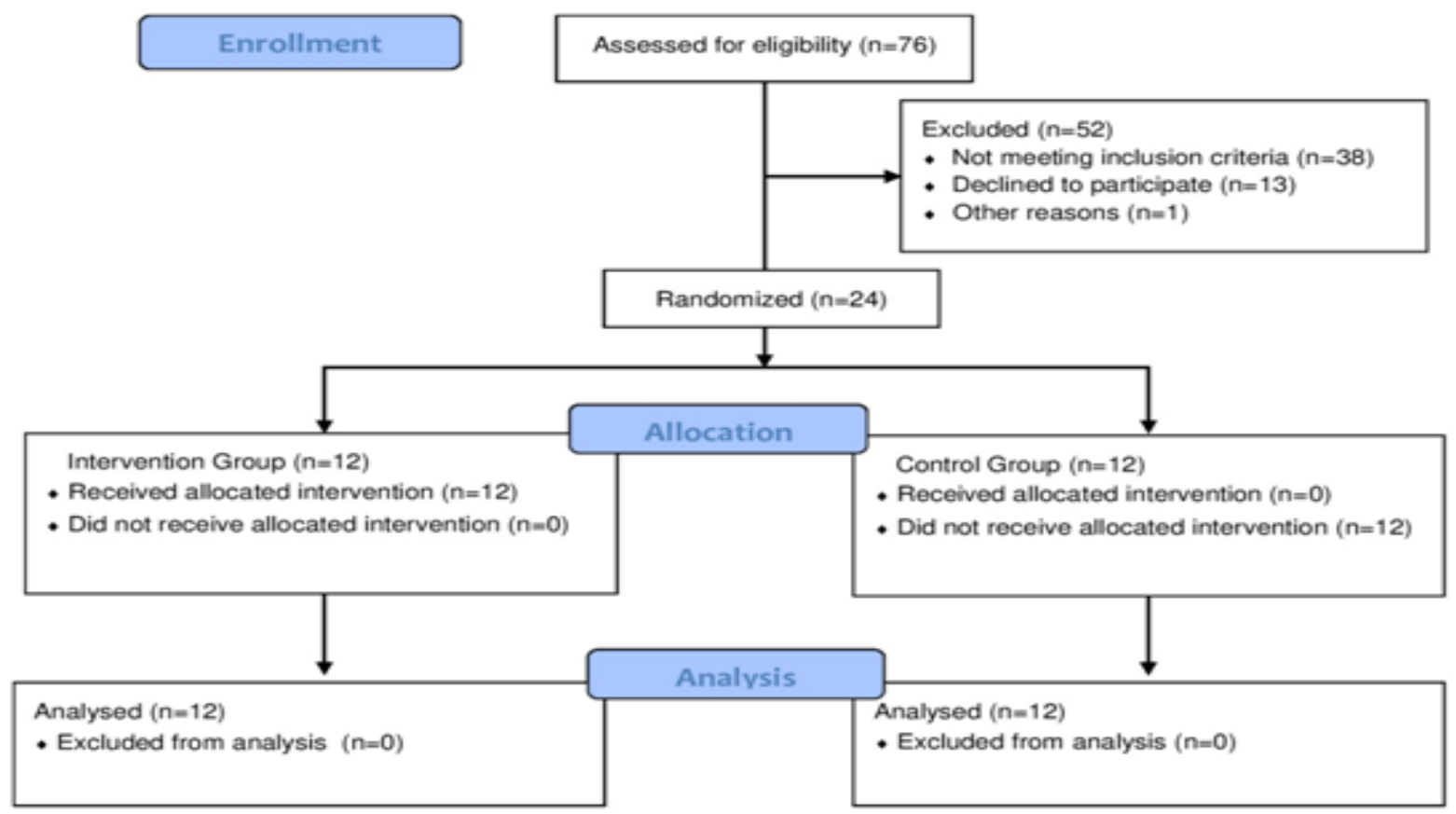

Figure 1. Flow Chart of The Study 
Participants were randomized into exercise and control groups with computer aided randomization method. Computer aided randomization was performed using Statistical Package for Social Sciences, version: 22.0, Chicago, IL (SPSS) program. Individuals were enumerated by the researcher based on participation sequence and were registered into the program. Computer program distributed the participants randomly and in equal numbers into exercise and control groups (SPSS Tutorials, 2014).

\section{Intervention}

Therapeutic exercises and oral notification was applied to the exercise group. As part of oral notification, positive effects of exercises on joint stiffness and functions were described in a 45 minutes meeting. Therapeutic exercise program was applied by the researcher physiotherapist on alternating days (Monday - Wednesday - Friday) for eight weeks. Programs of those who were unable to attend some sessions due to physical (hemorrhage-pain) or social reasons was extended equal to the number of missed sessions (same frequency). Exercise applications were performed in the gymnasium affiliated to the university in which the equipment used in the study was included. For the participants in exercise group two-phase therapeutic exercises program including as; resistant exercises to enhance muscular strength, stretching exercises to increase flexibility and balance exercises to improve balance was applied (Cuesta-Barriuso et al., 2017). The first phase comprised of the first four weeks, the second phase consisted of the last four weeks. Sessions in both phases commenced with warm-up period including aerobic walking and active range of motions (AROM). Aerobic warm-up period was composed of walking on the treadmill for 10 minutes with $5 \mathrm{~km} / \mathrm{h}$ in the first phase, 15 minutes with the same speed in the second phase. AROM was, on the other hand, applied in both phases including major joints (shoulder, elbow, hip, knee, ankle and spinal joints) and repeating 10 times.

Resistant exercises were implemented in both phases using yellow Therabant ${ }^{\mathbb{R}}$. On muscles affecting shoulder, elbow, knee and ankle $(\mathrm{m}$. deltoideus, $\mathrm{m}$. biceps brachii, $\mathrm{m}$. triceps brachii, $\mathrm{m}$. quadriceps femoris, hamstrings, m. tibialis anterior and triceps surae) resistant exercises were performed \%40 of 1 repetitive maximum (1RM) in the first phase recurring 10 times and for 3 sets, whereas in the second phase, $\% 60$ of $1 \mathrm{RM}$ recurring 15 times and again for 3 sets. Stretching exercises were done by the participants in static type, after warm-up period and at the end of the session. Static stretching was applied on shoulder posterior capsule as well as pectoral region, elbow flexors, hamstrings and triceps surae muscles. Stretching exercises including $15 \mathrm{sec}$ duration$10 \mathrm{sec}$ interval for 3 sets during the first phase, $20 \mathrm{sec}$ duration-10sec interval for 4 sets during the second phase were performed. Participants applied balance exercises bilateral upright and knees in semiflexion position. Balance training was in the form of weight-bearing or swinging anteriorposterior-right and left directions. Participants were provided with balance exercises including $15 \mathrm{sec}$ duration-30sec relaxation on static hard surface for 5 sets during the first phase, whereas in the second phase, the same exercises were applied but on a soft surface (on a BOSU ${ }^{\circledR}$ ball) (Table 1). Control group received only verbal information about positive effects of exercises on hemophilic arthropathy, in same meeting with exercise group. No physical exercise was applied to individuals in this group.

\section{Outcome measures}

Tampa Scale of Kinesiophobia (TSK), Hemophilia Adult Quality of Life Questionnaire (Hem-A-Qol) and Short Form-36 (SF-36) were used in the study. These evaluation scales were applied on the participants of both groups before and at the end of the (after eight weeks) study by the researcher physiotherapist. TSK is a questionnaire which evaluates pain or fear related to previous injuries and it consists of 17 questions. With this questionnaire, avoidance of physical activity with the fear of pain or injury risk is examined. In this questionnaire, likert scale from 1 to 4 (1: strongly disagree, 4: completely agree) is used. Turkish validity and reliability study was performed by Tunca Y1lmaz et al. (Tunca Yilmaz et al., 2011). According to Vlaeyan et al., the total of 37 points and more indicate high kinesiophobia (Vlaeyan et al., 1995).

Hem-A-Qol is a valid questionnaire which evaluates the HR-QoL of adult hemophilic individuals and which is translated into more than 60 languages (von Mackensen et al., 2005). This questionnaire consists of 10 sections (physical health, feeling, view of oneself, sports and leisure, work and school, dealing with hemophilia, 
treatment, future planning, family planning, relationship and sexuality) and 46 questions. Each question is scored with the likert scale from 1 to 5 (1: never, 5: always). There is an inverse proportion between the score received from this test and the quality of life. The higher the scores participants receive from this test, the less their quality of life is (Rambod et al., 2018). Its translation into Turkish and validation was conducted by Mercan et al. (Mercan et al., 2010).

SF-36 is a quality of life questionnaire and has 8 sections (physical function, physical role, pain, general health, life force, social activities, emotional functions and mental health) and 36 questions. In this questionnaire, scoring is from 0 to 100 . There is a direct proportion between the point received and the quality of life. The fact that the points received from this questionnaire are high shows that they have a good quality of life. SF-36 is a valid questionnaire that can be used in evaluating hemophilic individuals' quality of life (von Mackensen et al., 2013). Turkish validity and reliability studies are conducted for many different illnesses

Table 1. Therapeutic Exercise Program

\begin{tabular}{|c|c|c|}
\hline Exercise & $\begin{array}{c}\text { Phase I } \\
(0-4 . \text { weeks })\end{array}$ & $\begin{array}{c}\text { Phase II } \\
\text { (5.-8. weeks) }\end{array}$ \\
\hline $\begin{array}{l}\text { Aerobic Walking } \\
\text { (warm up) }\end{array}$ & $\begin{array}{l}-10 \mathrm{~min}-5 \mathrm{~km} / \mathrm{h} \\
-\mathrm{AROMs} \times 10\end{array}$ & $\begin{array}{l}-15 \mathrm{~min}-5 \mathrm{~km} / \mathrm{h} \\
- \text { AROMs x } 10\end{array}$ \\
\hline Resistive exercises & $\begin{array}{l}\text { \%40 1RM x10 repetitions } \times 3 \text { sets } \\
\text {-Material: Yellow Therabant }{ }^{\mathbb{R}}\end{array}$ & $\begin{array}{l}\text { - \%60 1RM x15repetitions x } \\
\text { 3sets } \\
\text { - Material: Yellow Therabant }{ }^{\mathbb{B}}\end{array}$ \\
\hline Stretching exercises & $\begin{array}{l}\text {-Type: Static } \\
\text { - } 15 \text { sec x } 3 \text { sets }\end{array}$ & $\begin{array}{l}\text {-Type: Static } \\
\text { - 20sec x } 4 \text { sets }\end{array}$ \\
\hline Balance exercises & $\begin{array}{c}\text { - Ground: Hard and static } \\
\text {-Material: None } \\
\text { - Duration: } 15 \mathrm{sec} \text { weight } \\
30 \mathrm{sec} \text { rest }\end{array}$ & $\begin{array}{l}\text { - Ground: Soft } \\
\text {-Material: BOSU }{ }^{\circledR} \text { ball } \\
\text { - Duration: } 15 \mathrm{sec} \text { weight } \\
\text { bearing - } 30 \mathrm{sec} \text { rest }\end{array}$ \\
\hline
\end{tabular}

AROM (Active range of motion) RM (Repetitive maximum)

\section{Statistical Analysis}

For the statistical analysis, Statistical Package for Social Sciences, version:22.0, Chicago, IL (SPSS) program was used. Shapiro-Wilk Test revealed that data was normally distributed ( $p>.05)$. Sociodemographic-clinic and physical characteristics of the participants were compared by $t$ test and $x^{2}$ test and were demonstrated as mean \pm standard deviation (sd) and mean (\%). In the comparison of the delta (difference between the posttest and the first test) of SF-36, Hem-AQol and TSK scores, $t$ test was used. $p<0.05$ was considered to be a statistically meaningful value. The effect sizes (Cohen d) between groups were also calculated. The effect sizes are presented with their \%95 Confidence Interval (CI). A score less than 0.4 represents small effect; between 0.4 and 0.8 , a moderate effect; and greater than 0.8 , a large effect.

\section{RESULTS}

Data of 24 individuals were analyzed. There were no participants who were unable to complete the study for any reasons (such as pain, hemorrhage, social reasons). However, two patients discontinued the program because of the pain in their knees until their symptoms were relieved (the first one on the second week, the second one on the sixth week of the program). During the exercise program, no participant reported to have hemorrhage in any of the joints. 


\section{Physical and Sociodemographic- Clinical Characteristics}

Participants' average of age in control group was specified as $25.5 \pm 8.8$ years, in exercise group, as $26.3 \pm 6.6$ years and body mass index (BMI) in control group as $22.0 \pm 3.5 \mathrm{~kg} / \mathrm{m}^{2}$, in exercise group, as $24.9 \pm 5.7 \mathrm{~kg} / \mathrm{m} 2$. With all participants, at least in one joint, arthropathy was observed where this number in control group was calculated as $2.1 \pm 1.6$ and as $2.0 \pm 1.8$ in exercise group. All individuals notified they were literate and received school education in various levels, besides, half of them were married and the rest were single. When looked upon clinical values, 17 of the participants were seemed to have severe (factor activity: $<\% 1$ ), 7 of them mild (factor activity: \%1-5) hemophilia and 17 to be diagnosed with hemophilia A, 7 with hemophilia B. In all physical and sociodemographic-clinical data, there was not a significant difference between groups $(p>0.05)$ (Table 2).

Table 2. Physical and Sociodemographic-Clinical Characteristics of The Participants

\begin{tabular}{|c|c|c|c|c|c|}
\hline \multicolumn{6}{|l|}{ Physical characteristics } \\
\hline & Group & $\mathrm{n}$ & $x$ & $\mathrm{Sd}$ & $\mathrm{p}$ \\
\hline \multirow[t]{2}{*}{ Age (year) } & Control & 12 & 25,5 & 8,8 & \multirow[t]{2}{*}{,772 } \\
\hline & Exercise & 12 & 26,3 & 6,6 & \\
\hline \multirow[t]{2}{*}{$\overline{B M I}\left(\mathrm{~kg} / \mathrm{m}^{2}\right)$} & Control & 12 & 22,0 & 3,5 & \multirow[t]{2}{*}{225} \\
\hline & Exercise & 12 & 24,9 & 5,7 & \\
\hline \multirow[t]{2}{*}{ Target joints (n) } & Control & 12 & 2,1 & 1,6 & \multirow[t]{2}{*}{,680 } \\
\hline & Exercise & 12 & 2,0 & 1,8 & \\
\hline \multicolumn{2}{|c|}{ Sociodemographic-clinical characteristics } & $\mathrm{n}$ & \multicolumn{2}{|c|}{$(\%)$} & $\mathrm{p}$ \\
\hline \multirow[t]{2}{*}{ Education, n (\%) (PS/HS/Uni) } & Control & $1 / 7 / 4$ & $8,3 / 5$ & 33,3 & \multirow[t]{2}{*}{,324 } \\
\hline & Exercise & $0 / 6 / 6$ & & & \\
\hline \multirow[t]{2}{*}{ Marital status (Single/Married) } & Control & $5 / 7$ & 41 , & & \multirow[t]{2}{*}{424} \\
\hline & Exercise & $7 / 5$ & 58, & & \\
\hline \multirow[t]{2}{*}{ Severity (severe/medium) } & Control & $9 / 3$ & 75 , & & \multirow[t]{2}{*}{,660 } \\
\hline & Exercise & $8 / 4$ & 66 , & & \\
\hline \multirow[t]{2}{*}{ Type (A/B) } & Control & $9 / 3$ & 75 , & & \multirow[t]{2}{*}{,660 } \\
\hline & Exercise & $8 / 4$ & 66, & & \\
\hline
\end{tabular}

BMI (Body massindex) PS (Primary school) HS (High school) Uni (University) x (mean) sd (Standart deviation)

\section{Kinesiophobia}

Before the exercise program, kinesiophobia level of the participants in control group was evaluated as $38.0 \pm 5.7$ and in exercise group as 43.5 \pm 5.9 . Between groups in kinesiophobia level, there was a significant difference in favor of the control group $(p<0.05)$. After the exercise program, the kinesiophobia level was seemed to be $39.4 \pm 5.3$ in control group and $41.0 \pm 5.3$ in exercise group. While the kinesiophobia level of the control group was increasing, that of the exercise group seemed to decrease. Between the groups after the exercise program, a meaningful variation developed in favor of the exercise group $(p<0.05)$ (Table 3).

\section{HR-QoL}

While the total Hem-A-Qol score was $42.9 \pm 9.9$ in control group before the exercise program, it was $42.0 \pm 10.3$ in exercise group. There was not a meaningful difference between the groups in terms of Hem-A-Qol value $(p>0.05)$. It was indicated after the evaluation done at the end of the exercise program that the total Hem-A-Qol value increased to $44.3 \pm 7.4$ in control group, whereas it decreased to $40.8 \pm 9.8$ in exercise group. Besides, there was a difference clinically in favor of the exercise group in total Hem-A-Qol value, whereas this difference was not statistically meaningful $(p>0.05)$ (Table 3$)$.

Before the therapeutic exercise program, the total SF-36 score of the control group was evaluated as $70.3 \pm 15.3$, that of the exercise group was calculated as $64.7 \pm 17.4$ and there was not a 
significant difference between groups in terms of SF-36 total score $(p>0.05)$. It was seen at the end of the exercise program that the total SF-36 score of the control group decreased to $62.8 \pm 18.8$ and the score of the exercise group increased to
73.3 \pm 20.6 . At the end of the exercise program, there was a significant difference in SF-36 total score in favor of the exercise group $(p<0.05)$ (Table 3).

Table 3. Kinesiophobia and Health Related Quality of Life Scores of The Participants.

\begin{tabular}{|c|c|c|c|c|c|c|c|c|c|c|c|}
\hline \multicolumn{6}{|c|}{ Pre-exercise } & \multicolumn{5}{|c|}{ Post-exercise } & \multirow[b]{2}{*}{$\begin{array}{l}\text { Cohen d } \\
(\% 95 \text { CI })\end{array}$} \\
\hline & Group & $\mathbf{n}$ & $x$ & sd & $\mathbf{p}$ & Group & $\mathbf{n}$ & $x$ & sd & $\mathbf{p}$ & \\
\hline \multirow[t]{2}{*}{ TSK } & Control & 12 & 38,0 & 5,7 & \multirow[t]{2}{*}{, $033 *$} & Control & 12 & 39,4 & 5,3 & \multirow[t]{2}{*}{, $049 *$} & \multirow[t]{2}{*}{$\begin{array}{l}0.86 \\
(0.17 \text { to } 1.13)\end{array}$} \\
\hline & Exercise & 12 & 43,5 & 5,9 & & Exercise & 12 & 41,0 & 5,3 & & \\
\hline
\end{tabular}

\begin{tabular}{|c|c|c|c|c|c|c|c|c|c|c|}
\hline $\begin{array}{l}\text { Hem-A- } \\
\text { Qol }\end{array}$ & Control & 12 & 42,9 & 9,9 & ,985 & Control & 12 & 44,3 & 7,4 & $\begin{array}{l}0.58 \\
(-0.37 \text { to } 2.02)\end{array}$ \\
\hline & Exercise & 12 & 42,0 & 10,3 & & Exercise & 12 & 40,8 & 9,8 & \\
\hline
\end{tabular}

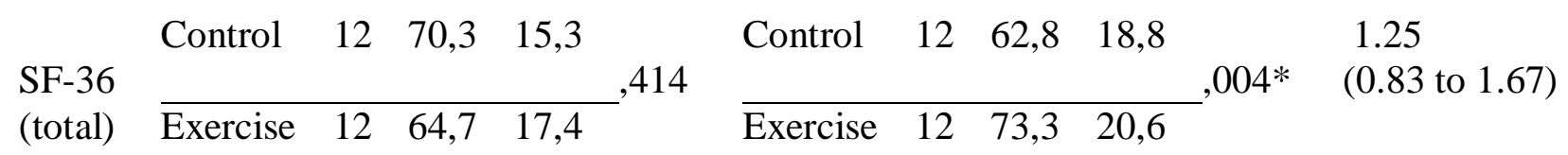

Cohen d relation (between groups effect size) CI (Confidence Interval) TSK (Tampa Scale of Kinesophobia) SF-36 (Short Form-36) Hem-A-Qol (Haemophilia Adult Quality of Life Questionnaire) $x$ (mean) sd (Standart deviation) $(*)(p<0.05)$

\section{DISCUSSION}

In this study where the effects of therapeutic exercises investigated on kinesiophobia and HRQoL of adult hemophilic individuals, exercise group reflected a significant improvement in both parameters when compared to the control group. In musculoskeletal diseases, a decrease of 2 (95\% CI: $>2 ;>2$ ) in TSK (Monticone et al., 2017) and an increase of $12 \%$ in SF-36 (Angst et al. 2001) was determined as minimal clinical important difference. Considering these values, it is seen that both parameters improve clinically in the exercise group.

Kinesiophobia is described as an extreme irrational and weakening fear about carrying out a physical movement due to the feeling of frailty against a painful injury or the possibility of being injured again (Kori et al., 1990). It generally springs out based directly on a bad experience or social learning (Meier et al., 2015). As in many other illnesses, avoidance of physical activity because of kinesiophobia is frequently confronted in hemophilia, as well (Steimer, 2002\& Lehmier et al., 2018). Pain, fear of injury-hemorrhage and lack of motivation are some of the reasons for the development of this phenomenon in hemophilic individuals (Lehmier et al., 2018). In literature, there are studies in which positive effects of functional exercises on kinesiophobia are shown (Monticone et al., \& Cruz Diazet et al., 2018). In addition, no study aiming to enhance the kinesiophobia phenomenon on hemophilic individuals is seen. We believe, in our study, by means of a good tolerance of therapeutic exercises by individuals, the level of kinesiophobia decreased. However, since the exercise program was limited to eight weeks, the level of kinesiophobia of individuals in the exercise group remained above normal. The increase in the kinesiophobia level of the control group which do not perform regular exercises supports the view that avoidance behaviors raise the level of kinesiophobia more. This situation is another indication to prove the importance of therapeutic exercises over kinesiophobia management. 
In hemophilic individuals, the severity of hemophilia, frequency of hemorrhage, type of treatment and joint problems constitute physical conditions (Cuesta-Barriusoet et al., 2017) and characters of individuals, their demographic situations and status of life constitute social conditions (Bullinger et al., 2008) affecting the quality of life. When literature is observed, the general view is towards that the HR-QoL of hemophilic individuals is worse than the rest of the population. However, there are studies against this argument (Fischeret et al., 2005). In our study, in parallel with the widespread view, hemophilic individuals' HR-QoL was determined to be lower than the normal population. Main reasons of this situation are inadequacies in physical conditions and pain. We think that positive effects of therapeutic exercises on physical fitness parameters (Cuesta-Barriuso et al., 2017 \& von Mackensen et al., 2013) and that they decrease the level of pain enhance the HR-QoL of hemophilic individuals.

Individuals being informed about their illnesses and the strategies to cope with their problems affect their emotional and physical conditions positively (Llewellynet et al., 2005). Cuesta et al. report in their study that improvement in HR-QoL of hemophilic individuals was provided giving information about the complications of hemophilia, benefits of therapeutic exercises and strategies to cope with the illness. They described this situation with the increase in individuals' skills to control and manage hemophilia (Cuesta-Barriusoet et al., 2017). It occurred differently in our study that there was no improvement in the HR-QoL of the control group receiving just verbal education. We believe no improvement was seen due to the fact that the duration of verbal education was low and that it was not supported with physical activity programs.

It is essential that exercises applied on hemophilic individuals do not cause hemarthrosis and should be well tolerated by patients (Calatayud et al., 2019). In literature, various results in terms of exercise programs' creating the risk of hemarthrosis, particularly including strengthening education, were stated. Heijenen et al. notified that strengthening exercises they used for the treatment of hemophilic arthropathy caused hemorrhage in some patients (Heijnen L and de Kleijn, 1999). Other researchers, on the other hand, inferred that these exercises did not cause hemarthrosis and, on the contrary, they decreased the frequency of hemorrhage (Tiktinskyet et al., 2002 \& Calatayud et al., 2019). In our study, participants in the exercise group did not notify any hemorrhage based on exercises during the therapeutic exercise program, in the course of the exercise or within the same day. When data obtained from this study and other studies are considered, it can be concluded that therapeutic exercises are safe for hemophilic individuals.

\section{Limitations}

There are some limitations in this study. Firstly, long-term follow-up of patients could not be performed. Long-term patient follow-up is necessary to determine whether the effects of treatment programs are sustained. Second limitation is that only subjective tests were used in the study. Even though there some studies conducted regarding this issue (Calatayud et al., 2019\&von Mackensen et al., 2013), subjective tests have to be supported by objective tests measuring physical parameters. Third limitation is that there was no blinding in this study. Blinding is a key methodological procedure to decrease risk of bias (Hróbjartsson et al., 2014). Because of these limitations, these results obtained in the study are required to be supported by prospective randomized studies in the long term.

\section{CONCLUSIONS}

In this study a decrease in kinesiophobia and increase in HR-QoL in adult hemophilic individuals were observed. Therapeutic exercises can be recommended in the management of kinesiophobia and HR-QoL deficiency in hemophilia.

\section{REFERENCES}

Angst, F., Aeschlimann, A., \& Stuck,i G. (2001). Smallest detectable and minimal clinically important differences of rehabilitation intervention with their implications for required sample sizes using WOMAC and SF-36 quality of life measurement instruments in patients with osteoarthritis of the lower extremities. Arthritis Rheum. 2001 45(4):384-91.

Bullinger, M., \& von Mackensen, S. (2008). Psycho-social determinants of quality of life 
in children and adolescents with haemophilia-a cross-cultural approach. Clin Psychol Psychother. 15(3): 164-172.

Calatayud, J., Pérez-Alenda, S., Carrasco, JJ., Escriche, A., Cruz-Montecinos, C., Andersen, LL., et al. (2019). Upper-Body Exercises With External Resistance Are Well Tolerated and Enhance Muscle Activity in People With Hemophilia. Phys Ther. Apr 1;99 (4):411-419.

Cruz-Díaz, D., Romeu, M., Velasco-González, C., Martínez-Amat, A., \& Hita-Contreras, F. (2018). The effectiveness of 12 weeks of Pilates intervention on disability, pain and kinesiophobia in patients with chronic low back pain: a randomized controlled trial. Clin Rehabil. Sep;32(9):1249-1257.

Cuesta-Barriuso, R,, Torres-Ortuño, A., NietoMunuera, J., \& López-Pina, JA. (2017). Effectiveness of an Educational Physiotherapy and Therapeutic Exercise Program in Adult Patients With Hemophilia: A Randomized Controlled Trial. Arch Phys Med Rehabil. May;98(5):841-848.

Fischer, K., de Kleijn, P., Negrier, C., et al. (2016). The association of haemophilic arthropathy with health-related quality of life: a post hoc analysis. Haemophilia;22(6):833-840.

Fischer, K., Van der Bom, JG., MauserBunschoten, EP., Roosendal, G., \& Van dem Berg, HM. (2005). Effects of haemophilic arthropathy on health related quality of life and socio-economic parameters. Haemophilia;11:43-8.

Hartl, HK., Reitter, S., Eidher, U., Ramschak, H., Ay, C., Pabinger I. (2008). The impact of severe haemophilia on the social status and quality of life among Austrian haemophiliacs. Haemophilia;14(4): 703-708.

Heijnen, L., \& de Kleijn, P. (1999). Physiotherapy for the treatment of articular contractures in haemophilia. Haemophilia; 5(Suppl.1): 169.

Hróbjartsson, A., Emanuelsson, F., Skou Thomsen, AS., Hilden, J., \& Brorson S. (2014). Bias due to lack of patient blinding in clinical trials. A systematic review of trials randomizing patients to blind and nonblind sub-studies. Int $J$ Epidemiol. 43(4):1272-83.
Kori, S., Miller, R., \& Todd, DD. (1990). Kinesiophobia: a new view of chronic pain behavior. Pain Manag;3:35-43.

Lehmeier, A., Ar, MC., Sadri, S., Yürüyen, M., Başlar, Z. (2018). Participation in Physical and Sportive Activities among Adult Turkish People with Hemophilia: A Single-Center Experience. Turk $J$ Haematol. Mar 1;35(1):81-82.

Llewellyn, CD., Miners, AH., Lee, CA., Harrington, C., \& Weinman, J. (2003). The illness perceptions and treatment beliefs of individuals with severe haemophilia and their role in adherence to home treatment. Psychol Health;18:185-200.

Luque-Suarez, A., Martinez-Calderon, J., \& Falla, D. (2018). Role of kinesiophobia on pain, disability and quality of life in people suffering from chronic musculoskeletal pain: a systematic review. Br J Sports Med. Apr 17.

Meier, ML., Stämpfli, P., Vrana, A., et al. (2015). Fear avoidance beliefs in back pain-free subjects are reflected by amygdala-cingulate responses. Front Hum Neurosci;9:1-10.

Mercan, A., Sarper, N., Inanir, M., Mercan, HI., Zengin, E., Kiliç, SÇ., et al. (2010). Hemophilia-Specific Quality of Life Index (Haemo-QoL and Haem-A-QoL questionnaires) of children and adults: result of a single center from Turkey. Pediatr Hematol Oncol. Sep;27(6):449-61.

Monticone, M., Ferrante, S., Rocca, B., Salvaderi, S., Fiorentini, R., Restelli, M., et al. (2013). Home-based functional exercises aimed at managing kinesiophobia contribute to improving disability and quality of life of patients undergoing total knee arthroplasty: a randomized controlled trial. Arch Phys Med Rehabil. Feb;94(2):231-9.

Monticone, M., Ambrosini, E., Rocca, B., Foti, C., $\&$ Ferrante, S.(2017) Responsiveness and minimal clinically important changes for the Tampa Scale of Kinesiophobia after lumbar fusion during cognitive behavioral rehabilitation. Eur $J$ Phys Rehabil Med. 53(3):351-358.

Rambod, M., Sharif, F., Molazem, Z., Khair, K., \& von Mackensen, S. (2018). Health-Related Quality of Life and Psychological Aspects of Adults with Hemophilia in Iran. Clin Appl Thromb Hemost. Oct;24(7):1073-1081. 
Scalone, L., Mantovani, LG., Mannucci, PM., \& Gringery, A. (2006). The COCIS Study Investigators. Quality of life associated to the orthopaedic status in haemophilic patients with inhibitors. Haemophilia;12: 154-62.

Sethy, D., \& Sahoo, S. (2018). Kinesiophobia after complex regional pain syndrom etypeone in a case of stroke hemiplegia and effect of cognitive behavior therapy. Indian $\mathbf{J}$ Psychiatry. Jan-Mar;60(1):152-154.

SPSS Tutorials. (2014). How to Generate Random Numbers in SPSS. Access: 3 July 2019, https://ezspss.com/how-to-generate-randomnumbers-in-spss/

Steimer, T. (2002). The biology of fear- and anxiety-related behaviors. Dialogues Clin Neurosci;4:231-49.

Stephensen, D., Tait, RC., Brodie, N., et al. (2009). Changing patterns of bleeding in patients with severe haemophilia A. Haemophilia. 15:1210-1214.

Tiktinsky, R., Falk, B., Heim, M., \& Martinovitz, U. (2002). The effect of resistance training on the frequency of bleeding in haemophilia patients: a pilot study. Haemophilia; 8: 22-7.

Tunca Y1lmaz, Ö., Yakut, Y., \& Uygur, F. (2011). Tampa Kinezyofobi Ölçeği'nin Türkçe versiyonu ve test-tekrar test güvenirliği. Fizyoterapi ve Rehabilitasyon, 22(1), 44-49.

Vlaeyen, JW., Kole-Snijders, AM., Boeren, RG., \& van Eek, H. (1995). Fear of movement/(re) injury in chronic low back pain and its relation to behaviora lperformance. Pain;62:363-72.

Vlaeyen, J. W., Kole-Snijders, A. M., Rotteveel, A. M., Ruesink, R., \& Heuts, P. H. (1995). The role of fear of movement/(re) injury in pain disability. Journal of Occupational Rehabilitation, 5(4), 235-252. von Mackensen, S., Campos, IG., Acquadro, C., \& Strandberg-Larsen, M. (2013). Cross-cultural adaptation and linguistic validation of agegroup- specific haemophilia patientreported outcome (PRO) instruments for patients and parents. Haemophilia;19(2): e73-e83.

von Mackensen, S., Gringeri, A., Ravera, S., et al. (2005). Validation of the haemophiliaspecific quality of life questionnaire for adult patients with haemophilia (Haem-A-QoL). Haematologica.;20(2):115-156.

von Mackensen, S., \& Gringeri, A. (2009). Quality of life in hemophilia. In: Preedy VR, WatsonRReds. Handbook of Disease Burdens and Quality of Life Measures. Heidelberg: Springer, Vol. 3, Chapter 12: 1895-920.

White, GC., Rosendaal, F., Aledort, LM., Lusher, JM., Rothschild, C., \& Ingerslev, J. (2001). Definitions in hemophilia. recommendation of the scientific subcommittee on factor VIII andfactor IX of the scientific and standardization committee of the international society on thrombosis and haemostasis. ThrombHaemost; 85(3):560.

Witkop, M., Neff, A., Buckner, TW., et al. (2017). Self-reported prevalence, description and management of pain in adults with haemophilia: methods, demographics and results from the pain, functional impairment, and quality of life (P-FiQ) study. Haemophilia;23(4):556-565.

How to cite this article: Deniz, V. and A.Güzel, N. (2020). Do Therapeutic Exercises Improve Kinesophobia and Health-Related Quality of Life in Adult Hemophilia Patients? A Randomized Controlled Trial. Int J Disabil Sports Health Sci;3(1):11-19. https://doi.org/10.33438/ijdshs.690280 